\title{
VERIFICAÇÃO DA e-TaIIQ COMO INSTRUMENTO PARA MENSURAR A QUALIDADE NO VAREJO ELETRÔNICO
}

AN ANALYSIS OF THE E-TAIIQ AS INSTRUMENT FOR MEASURING QUALITY IN THE ELETRONIC RETAIL

\section{RESUMO}

Para entender a percepção do consumidor quanto ao varejo eletrônico em sua dimensionalidade, este artigo objetiva (a) verificar as propriedades psicométricas do instrumento e-TailQ no varejo eletrônico brasileiro e (b) identificar a associação dos fatores da escala com variáveis de marketing. A amostra é composta por 344 pessoas que já compraram bens no varejo eletrônico, e é configurada como uma survey do tipo bola de neve por conveniência. Os resultados demonstraram que o subconstruto qualidade de serviço ao consumidor foi eliminado da estrutura por apresentar altos valores omissos; a qualidade de design relacionou-se significativamente com satisfação, boca-a-boca e lealdade; e a variável qualidade de preenchimento teve relações positivas com lealdade, satisfação e boca-a-boca, mas negativa com valor.

\author{
Valter Afonso Vieira \\ Professor do Instituto de Ciências Sociais, Universidade de Brasília \\ valterafonsovieira@yahoo.com
}

Recebido em 24.05.2006. Aprovado em 09.05.2008

Avaliado pelo sistema double blind review

Editor Científico: Delane Botelho

\begin{abstract}
The service quality construct has been researched thoroughly in the marketing literature in terms of antecedents, consequences, dimensions, etc. However, not only research in electronic service quality still lacks of accomplishments, but also some definitions and dimensionality tests. Based on this context, the paper looked for understanding more the perceived quality in the electronic retail. Specifically, the paper verifies empirically the structure of the e-TailQ in the Brazilian electronic retail and associates its factors with loyalty, satisfaction, value and word-ofmouth. In terms of method, the sample contained just people that bought products in the electronic retail. It was a survey with a snowball sample of 344 people. The results demonstrated that the quality service consumer construct was eliminated by presenting high missing values; that quality design obtained three significant relationships from the four predicted - with satisfaction, word-of-mouth and loyalty; and that quality fulfillment which is the product description so that consumers receive what they exactly looking for - had significant relationships with loyalty, satisfaction and word-of-mouth and negative with value.
\end{abstract}

PALAVRAS-CHAVE Qualidade, varejo, internet, escala, lealdade.

KEYWORDS Quality, retail, internet, scale, loyalty. 


\section{INTRODUÇÃO}

No Brasil, uma pesquisa demonstrou que existem aproximadamente trinta milhões de usuários da Internet, indicando uma taxa de penetração da Internet de apenas 16\% (http://www.e-commerce.org.br/STATS.htm). Essa pequena taxa de penetração mostra que ainda existe muito que evoluir nesse segmento. O varejo eletrônico brasileiro, uma das potenciais fatias da Internet, movimentou 6,4 bilhões de reais em 2007, ou seja, 45\% a mais que o ano de 2006 (http://www.e-commerce.org.br/STATS.htm). Na verdade, o grande crescimento que o comércio eletrônico vem tendo nos últimos anos apresenta alguns desafios às empresas de varejo quanto ao diferencial para atrair e manter clientes dentro da rede, uma vez que custos de mudanças e busca de informação são bem menores na Internet quando comparados aos canais convencionais (HERNANDEZ, 2002).

Uma característica fundamental para o desenvolvimento do varejo eletrônico é aferir a qualidade do serviço prestado. No entanto, as pesquisas sobre a qualidade de serviços no varejo eletrônico ou mesmo a definição do construto são escassas. Afinal, o que é e como se define qualidade na arena virtual?

Para mensurar a qualidade eletrônica de varejistas, Wolfinbarger e Gilly (2003) sugeriram um instrumento denominado e-TailQ (Electronic Tail Quality). Nessa linha, este artigo verifica as propriedades psicométricas do instrumento e-TailQ no varejo eletrônico brasileiro. Para tanto, realizou-se uma série de testes para constatação da validade, confiabilidade e dimensionalidade do instrumento. Após isso, o trabalho também identificou a associação dos fatores de qualidade advindos do e-TailQ com as variáveis satisfação, lealdade, boca-a-boca e valor, ponderando a rede nomológica do instrumento.

Esta investigação traz uma contribuição empírica por apoiar o papel preditivo qualidade eletrônica sobre outras variáveis intencionais, ratificando os achados tradicionais da literatura. Além disso, reforça-se a teoria da multidimensionalidade da qualidade em ambiente eletrônico, confirmando os achados tradicionais do ambiente convencional.

O artigo estrutura-se da seguinte forma. A etapa seguinte analisa as definições e dimensões da qualidade em ambientes virtuais. Em seguida, as contribuições oriundas de outros trabalhos que verificaram a qualidade no ambiente eletrônico são discutidas e a metodologia é proposta. Posteriormente, apresentam-se os resultados da pesquisa, analisando as propriedades da escala e a associação dos fatores. Nas considerações finais, mostram-se os princi- pais resultados, os limites do trabalho e sugestões para pesquisas futuras.

\section{ESTUDOS SOBRE QUALIDADE NA INTERNET}

Inicialmente, Loiacono (2000), entrevistando consumidores, estudantes de graduação e designers de sites, propôs o instrumento chamado WEBQUAL, visando mensurar a qualidade de ambientes virtuais. As dimensões da qualidade eletrônica encontradas por aquele pesquisador foram: adequação de informação para a tarefa; interação da empresa com os consumidores; confiança; tempo de resposta; design; intuitividade; apelo visual e agradabilidade; inovatividade [senso de novo, criativo e único]; apelo para o fluxo emocional [perda do senso do mundo real na navegação]; comunicação integrada da imagem da empresa; processos de negócios [para realizar a compra]; e substitutibilidade [alternativas de contato clienteempresa].

Algumas críticas lançadas à escala WEBQUAL afirmam que são geradas informações de qualidade de serviços mais para designers do que informações experimentadas pelos clientes (PARASURAMAN, ZEITHAML e MALHOTRA, 2005). Em outras palavras, o instrumento teve por base uma análise mais profissional do que a concepção dos consumidores finais que buscam simplesmente uma compra.

Van-Riel, Liljander e Jurriens (2001) propuseram que o serviço eletrônico poderia ser dividido em cinco fatores: serviços principais, que representam a essência do site; serviços facilitadores, que auxiliam na criação dos serviços principais; serviços de suporte ou assistências eletrônicas, que correspondem ao auxílio adicional do varejista ao cliente; serviços complementares aos essenciais do portal; e interface com o usuário, que são as condições de familiaridade entre o site e o indivíduo. Van-Riel, Liljander e Jurriens (2001) diferem de Loiacono (2000) por pressuporem que são os aspectos de qualidade do serviço prestado, ao invés de características do site em si, que levam à satisfação. Desse modo, a soma dos dois trabalhos traz perspectivas divergentes, complementares e importantes para a estruturação da qualidade do varejista eletrônico.

Yoo e Donthu (2001), baseados em uma investigação com 141 estudantes, desenvolveram a escala SiteQual. O instrumento sugerido possui quatro dimensões: facilidade de uso; características de design; velocidade de processamento; e segurança.

A crítica feita ao trabalho de Yoo e Donthu (2001) está no fato de o mesmo carecer de uma real análise de 
compra em ambiente eletrônico, pois os estudantes apenas visitaram sites específicos e, após isso, avaliaram os mesmos, ou seja, a mesma limitação da pesquisa de Loiacono (2000).

Gefen (2002, p. 40) buscou estender a escala SERVQUAL para o ambiente eletrônico, analisando-a por meio de compras eletrônicas. Segundo o autor, os resultados apresentaram que as "cinco dimensões (tangibilidade, empatia, confiabilidade, capacidade de resposta e segurança) se fundiram em três, sendo elas: (1) tangibilidade; (2) uma dimensão combinada de capacidade de resposta, confiabilidade e segurança; e (3) uma de empatia". Os resultados ainda indicaram validade discriminante e convergente dessas três novas dimensões. Todavia, esse resultado discriminatório é "contraditório" ao encontrado no ambiente convencional por Parasuraman, Zeithaml e Berry (1988), pois a escala que visa a mensurar qualidade no ambiente real não está adequada conceitual e dimensionalmente. Por exemplo, como é compreendida a dimensão combinada de capacidade de resposta, confiabilidade e segurança?

Além do mais, uma adaptação de uma escala de um ambiente para outro totalmente diferente não reflete exatamente a realidade deste último. Portanto, um instrumento elaborado especificamente para avaliar a qualidade eletrônica poderia gerar melhores resultados quando comparado às escalas de qualidade adaptadas de ambientes convencionais.

Francis e White (2002) criaram um instrumento de mensuração da qualidade eletrônica com 302 compradores australianos, baseando nas expectativas versus desempenho. Esses autores evoluíram das limitações de visita de Loiacono (2000) e Yoo e Donthu (2001), por utilizarem a compra em si, e também dos obstáculos de adaptação de instrumento de Gefen (2002), por assumirem uma escala nova.

O instrumento proposto foi denominado PIRQUAL e inclui seis dimensões conhecidas: funcionalidade da loja eletrônica; entrega dos produtos; serviço ao consumidor; condições de propriedade; descrição dos atributos do produto; e segurança.

Uma consideração importante no trabalho de Francis e White (2002) é a utilização de intenções comportamentais como medida dependente de intenções da revisita à página. Os resultados demonstraram valores significativos para todas as dimensões exceto para descrição dos atributos do produto. Portanto, Francis e White (2002) mostram que os fatores acima afetam a intenção comportamental do internauta de voltar ao site.

Zeithaml, Parasuraman e Malhotra (2000), por meio de uma revisão de literatura sobre o tema, indicaram que existem alguns "critérios pelos quais consumidores avaliam os sites e a qualidade". Esses critérios são agrupados da seguinte maneira: informação e disponibilidade do conteúdo; facilidade do uso; privacidade e segurança; estilo gráfico; e cumprimento e confiança. A intenção principal de Zeithaml, Parasuraman e Malhotra (2000) foi a de apresentar o que se faz e o que ainda falta ser realizado em termos de qualidade no ambiente virtual. Assim, a proposta foi apenas conceitual e não empírica.

Dando continuidade, Yang e Fang (2004), baseando-se em experiência online de serviços varejistas, descobriram 52 itens que corresponderiam a 16 grandes dimensões de qualidade online. Os resultados demonstraram as seguintes dimensões: capacidade de resposta; confiabilidade; credibilidade; competência; acesso; cortesia; melhoramento contínuo da comunicação; portfólio de serviço; conteúdo; condições de tempo; segurança; aspecto de facilidade de uso; confiabilidade do sistema; e flexibilidade do sistema. Um resultado interessante do trabalho é que os melhores preditores da satisfação eletrônica são as dimensões de resposta, confiabilidade do serviço e competência. No outro extremo, os melhores explicadores da insatisfação são as dimensões de resposta, confiabilidade do serviço e competência. Diferentemente dos outros trabalhos, Yang e Fang (2004) utilizaram apenas uma análise de freqüência e não testes de correlação. Outra limitação está no tamanho do instrumento, 52 itens, podendo ser de difícil aplicação.

Wolfinbarger e Gilly (2003), baseando-se nas limitações e sugestões de Zeithaml, Parasuraman e Malhotra (2000), e no ponto das expectativas versus desempenho de Francis e White (2002), fizeram uma proposta de medição da qualidade, propondo a escala e-TailQ. Essa sugestão foi baseada em grupos de foco online e offline e em uma survey. As dimensões foram objetivadas na experiência de compra eletrônica e não na interação com o site, condição essa que cobre a lacuna deixada pelos trabalhos anteriores. Essas dimensões são a base da escala e-TailQ que é analisada neste artigo. Os resultados apontaram as seguintes dimensões:

- qualidade de design: elementos da experiência com o site, incluindo navegação, personalização, ajuda, busca por informações, seleção de produto e processo de fechar o pedido;

- qualidade de preenchimento: descrição precisa de um produto de modo que consumidores recebam o que eles buscam, e entrega do produto correto dentro do tempo prometido;

- qualidade de segurança/privacidade: segurança no 
sistema de pagamento e privacidade no momento de dividir a informação; e

- Qualidade de serviço ao consumidor: resposta, ajuda e desejo de responder às questões dos clientes.

Algumas conclusões dos autores foram: (i) A dimensão segurança/privacidade teve impacto não significativo na satisfação; isso talvez seja explicado pelo fato de os consumidores já esperarem aspectos de segurança em um site, fazendo com que isso não gere um nível prazeroso de contentamento relativo ao consumo (OLIVER, 1997). (ii) $\mathrm{O}$ construto segurança/privacidade teve impacto não significativo na lealdade e na atitude com o site, indicando que o aspecto de segurança pode não levar o indivíduo a ficar leal nem satisfeito com o site. Pelos resultados encontrados, cogita-se no papel da segurança como preditora da lealdade e satisfação, embora se reconheça a função crítica desse quesito para compras online. (iii) A dimensão serviço ao consumidor teve impacto não significativo na satisfação.

Em suma, a Tabela 1 apresenta os resultados da análise de regressão das dimensões propostas pela e-TailQ sobre um indicador de qualidade geral.

Os estudos anteriores auxiliam na compreensão das várias facetas do fenômeno qualidade em ambiente eletrônico, as definições empregadas, as variáveis exógenas e os resultados que podem convergir ou divergir daqueles apresentados aqui. Na próxima etapa, discute-se o método empregado para exame da e-TailQ.

\section{MÉTODO}

Para atingir os objetivos propostos, foi realizada uma tradução reversa das escalas utilizadas no estudo (MALHOTRA, 2001). Em seguida, realizou-se um pré-teste do questionário. No total, sete pesquisadores em marketing de uma grande universidade brasileira avaliaram e criticaram a versão prévia do instrumento. Modificações foram sugeridas e implementadas na nova versão.

Para a coleta de dados, optou-se pelo modo de levantamento (MALHOTRA, 2001). Assim, um questionário em HTML foi criado para a coleta de dados. O levantamento ocorreu pela Internet em domínio próprio e o questionário de autopreenchimento estava ligado a uma base de dados.

Neste artigo, a escala de qualidade e-TailQ versa sobre sites de modo geral e não sobre uma página específica. Isso significa que o respondente utilizou qualquer empresa de varejo eletrônico para avaliação do instrumento.

A amostra final continha apenas pessoas que já tinham comprado bens no varejo eletrônico. Uma pergunta filtro excluía as pessoas que não tinham comprado pela Internet, as quais poderiam não ter conhecimento para o preenchimento das respostas. A amostra foi do tipo bola de neve, fazendo um total de 344 pessoas.

As definições conceituais e operacionais das variáveis utilizadas na investigação são apresentadas nos Quadros 1 e 2. Todas as escalas foram mensuradas em sete pontos e as variáveis de intenções comportamentais possuem limitação por serem mensuradas com apenas um indicador.

Com relação à variável Qualidade do Quadro 1, observa-se no Quadro 2 a descrição dos itens Escala e-TailQ (escala de sete pontos), a média e o desvio-padrão, as variáveis referentes à qualidade design, segurança e preenchimento. A dimensão qualidade serviço ao consumidor será analisada logo a seguir.

\section{ANÁLISE DOS RESULTADOS DA PARTE I: PROPRIEDADES PSICOMÉTRICAS DA e-TailQ}

Inicialmente, dos 344 respondentes, 338 (98\%) já haviam comprado um produto ou serviço pela Internet. Assim,

Tabela 1 - Análise de regressão das dimensões da e-TailQ sobre a qualidade geral

\begin{tabular}{|l|c|c|c|c|}
\hline \multicolumn{1}{|c|}{ DIMENSÕES DA E-TAILQ } & AMOSTRA TOTAL & NAVEGADORES & $\begin{array}{c}\text { COMPRADORES } \\
\text { FREQÜENTES }\end{array}$ & $\begin{array}{c}\text { AMOSTRA } \\
\text { LIVROS/MÚSICA }\end{array}$ \\
\hline Qualidade de Design & $0,38^{*}$ & $0,61 *$ & $0,40 * *$ & $0,57 *$ \\
\hline Qualidade de Preenchimento & $0,42 *$ & $0,49 *$ & $0,22 * *$ & $0,22 * *$ \\
\hline Qualidade de Segurança & $-0,04$ (n.s.) & 0,10 (n.s.) & $0,20 * *$ & $-0,03$ (n.s.) \\
\hline Qualidade de Serviço Consumidor & $0,13 *$ & $-0,09$ (n.s.) & 0,08 (n.s.) & 0,05 (n.s.) \\
\hline R & $7 j$ justado & $81 \%$ & $63 \%$ & $63 \%$ \\
\hline
\end{tabular}

Fonte: Wolfinbarger e Gilly (2003), * $p<0,05 ; * *<0,01$; n.s. = não significativo; variável dependente qualidade geral. 
os seis casos que responderam nunca ter comprado eletronicamente foram excluídos do banco de dados devido a um possível não-conhecimento do processo de compra online.

A análise dos valores omissos mostrou que somente os itens relacionados ao construto qualidade serviço ao consumidor tiveram um percentual alto de dados ausentes: de $6 \%$ no item "Eu sinto que o site ' $x$ ' se preocupa com as necessidades dos consumidores", de $46 \%$ para o item "No site ' $\mathrm{x}$ ', as pessoas do atendimento online (chat) estão sempre prontas para atender o cliente", de $41,1 \%$ para o item "Quando eu tenho um problema, o site ' $x$ ' se apresenta interessado e sincero em resolver" e de $34,6 \%$ para o item "Dúvidas e solicitações são respondidas prontamente pela empresa". Todos os demais itens do questionário apresentaram um número de dados ausentes inferior a $7 \%$, estando dentro dos níveis aceitáveis sugeridos por Hair e outros (1998).
Um obstáculo encontrado inicialmente na estrutura e-TailQ foi o alto percentual de dados ausentes na dimensão qualidade serviço ao consumidor. Devido a esse problema, optou-se pela exclusão do construto da análise fatorial, pois para Kline (1998, p. 72) "um excesso de valores omissos, diga-se acima de $10 \%$, prejudica a análise de dados".

Caso a dimensão qualidade serviço ao cliente fosse mantida, mesmo com grande quantidade de valores omissos, uma estrutura fatorial limpa com quatro fatores surgiu $(\mathrm{KMO}=0,90)$, corroborando a escala original e com o trabalho de réplica feita por Caruana e Ewing (2006). A dimensão qualidade de design obteve 46,8\% de variância acumulada; a qualidade de segurança $9,8 \%$; a qualidade de serviço ao cliente $(\alpha=0,87) 7,29 \%$ e a qualidade de preenchimento $5,34 \%$, ou seja, $69,34 \%$ com todos autovalores maiores do que 1 .

Com relação à análise demográfica, dos 324 respon-

Quadro 1 - Definições operacionais e constitutivas das variáveis utilizados para a validade nomológica

\begin{tabular}{|c|c|c|}
\hline VARIÁVEL & DEFINIÇÃO CONSTITUTIVA & DEFINIÇÃO OPERACIONAL \\
\hline Lealdade & $\begin{array}{l}\text { Um profundo comprometimento para recomprar um } \\
\text { bem de maneira consistente no futuro, causando uma } \\
\text { compra repetida da mesma marca ou conjunto de mar- } \\
\text { cas apesar dos esforços de marketing para causar uma } \\
\text { mudança de comportamento (OLIVER, 1997). }\end{array}$ & $\begin{array}{l}\text { Um indicador baseado no trabalho de Zeithaml e outros } \\
\text { (1996), variando desde “muito baixa” até “muito alta”. } \\
\text { "A probabilidade de continuar comprando no site 'x' no } \\
\text { futuro é" }(M=5,75 \text {; desvio-padrão [d.p.] = } 1,52) \text {. }\end{array}$ \\
\hline Qualidade & $\begin{array}{l}\text { A extensão na qual um site facilita de modo efetivo } \\
\text { e eficiente a compra e a entrega do bem (ZEITHAML, } \\
\text { PARASURAMAN e MALHOTRA, 2000). }\end{array}$ & $\begin{array}{l}\text { Escala baseada nas quatro dimensões de e-TailQ de } \\
\text { Wolfinbarger e Gilly (2003). Três indicadores para preen- } \\
\text { chimento, nove para design, quatro para serviço ao con- } \\
\text { sumidor e quatro para segurança. Escala variando desde } \\
\text { "Discordo Totalmente" até “Concordo Totalmente”. }\end{array}$ \\
\hline Satisfação & $\begin{array}{l}\text { Uma resposta ao contentamento do consumidor, sig- } \\
\text { nificando um julgamento de que uma característica } \\
\text { do produto/serviço ofereceu (ou está oferecendo) um } \\
\text { nível prazeroso de contentamento relativo ao consumo } \\
\text { (OLIVER, 1997). }\end{array}$ & $\begin{array}{l}\text { Um indicador baseado no trabalho de Oliver (1980), } \\
\text { variando desde "Pouco Satisfeito" até "Muito Satisfei- } \\
\text { to". Meu grau de satisfação com o site 'x' é" }(M=5,82 \text {; } \\
\text { d.p. }=1,24) \text {. }\end{array}$ \\
\hline $\begin{array}{c}\text { Valor } \\
\text { Percebido }\end{array}$ & $\begin{array}{l}\text { A avaliação geral de utilidade de um serviço baseado } \\
\text { nas percepções do que é recebido sobre o que é dado } \\
\text { (ZEITHAML, 1988). }\end{array}$ & $\begin{array}{l}\text { Um indicador baseado no trabalho de Mathwick, Ma- } \\
\text { lhorta e Rogdon (2001), variando desde "Discordo To- } \\
\text { talmente" até "Concordo Totalmente". "Eu obtenho uma } \\
\text { boa relação de custo-benefício comprando no site 'x"” } \\
\text { (M=4,72; d.p. }=1,68) \text {. }\end{array}$ \\
\hline $\begin{array}{l}\text { Boca a } \\
\text { Boca }\end{array}$ & $\begin{array}{l}\text { Uma comunicação oral, de pessoa a pessoa entre um } \\
\text { emissor e o receptor (ARNDT, 1967). }\end{array}$ & $\begin{array}{l}\text { Um indicador baseado no trabalho de Gummerus e ou- } \\
\text { tros (2004), variando desde "Discordo totalmente" até } \\
\text { "Concordo Totalmente". "Eu recomendo fortemente o site } \\
\text { 'x' para meus amigos" ( } M=5,80 \text {; d.p. = } 1,41) \text { ". }\end{array}$ \\
\hline
\end{tabular}


dentes, os resultados apresentaram que 176 (54\%) eram do sexo masculino, 175 (54\%) tinham idade que variava entre 26 e 35 anos, e 111 (34,3\%) afirmaram possuir renda mensal acima de $\mathrm{R} \$ 5.000,00$; segue o grupo entre $\mathrm{R} \$ 1.001,00$ e $\mathrm{R} \$ 2.000,00$ (22,5\%). Quanto ao tempo em que efetuou a última compra online, a maioria respondeu tê-la feito havia menos de um mês (176 ou 54\%), seguido do período entre 2 e 3 meses ( 75 ou 23,1\%). A maioria afirmou gastar mais de 13 horas por semana navegando na Internet ( $f=132$ ou $41 \%$ ). Nesse contexto, os valores de tempo evidenciaram um período pequeno entre a última compra eletrônica e a resposta ao questionário, o que pode indicar uma boa precisão das opiniões dos indivíduos. O produto comprado com maior freqüência pelos respondentes foi livros ou revistas (110 ou 34\%), seguido de eletrônicos em geral ( 75 ou 23\%), passagem aérea (45 ou 14\%), serviços bancários ( 25 ou $7,7 \%$ ) e outros (69 ou 22\%).

Após as análises demográficas, a escala e-TailQ sofreu uma série de testes psicométricos para constatação da validade, confiabilidade e dimensionalidade. Inicialmente, a mesma foi submetida a análise fatorial exploratória com rotação Varimax. Desse modo, identificou-se um problema inicial de dimensionalidade. $O$ item "O site ' $\mathrm{x}$ ' apresenta informações detalhadas" foi retirado, pois possuía carga em fator não correspondente ao seu.

Os resultados dessa estrutura podem ser vistos na Tabela 2. A amostra foi bem adequada para a fatoração $(\mathrm{KMO}=0,89)$ e o teste de Bartlett se mostrou significativo $\chi^{2}=2.863,49$; g.l. $=105 ; p<0,000$. A variância total explicada pelos três construtos foi de $65,49 \%$. Isso representa que $65 \%$ da variância total apresentada pelas 15 variáveis iniciais podem ser representados simplesmente pelas três dimensões da e-TailQ, denominadas qualidade de design, qualidade de segurança e qualidade de preenchimento.

Por fim, esperava-se que os valores de confiabilidade da escala fossem maiores do que $\alpha \geq 0,70$, conforme é indicado pela literatura (MALHOTRA, 2001). Os resul-

\section{Quadro 2 - Descrição dos itens Escala e-TailQ (escala de sete pontos), média e desvio-padrão}
DIMENSÃO DESCRIÇÃO, MÉDIA E DESVIO-PADRÃO
Q5: 0 site " $x$ " apresenta informações detalhadas $(M=5,27$; d.p. $=1,39)$
Q4: Navegar pelo site " $x$ " não desperdiça meu tempo $(M=5,16$; d.p. $=1,54)$
Q3: É fácil e rápido completar uma transação de compra no site " $x$ " $(M=5,86 ;$ d.p. $=1,22)$
Qualidade de Design
Q2: 0 nível de personalização do site " $x$ " é ideal $(M=5,46$; d.p. $=1,36)$
Q1: A organização e o layout do site " $x$ " facilitam a procura de produtos $(M=5,15 ;$ d.p. $=1,40)$
Q6: 0 site " $x$ " tem um apelo visual muito bom $(M=5,15$; d.p. $=1,40)$
Q7: Eu posso navegar rapidamente e de maneira precisa dentro do site " $x$ " $(M=5,46$; d.p. $=1,36)$
Q8: A aparência do site " $x$ " parece ser profissional $(M=5,86$; d.p. $=1,22)$
Q9: 0 site " $x$ " tem uma ampla variedade de produtos que acaba me interessando $(M=5,55$; d.p. $=1,53)$

\section{Qualidade de Segurança}
Qualidade de Preenchimento
Dimensão
Qualidade
Serviço ao
Consumidor
Q3: Eu sinto que minha privacidade está protegida utilizando esse site " $x$ " $(M=5,46 ;$ d.p. $=1,48)$
Q4: Eu me sinto seguro quando eu estou fazendo transações/compras com o site " $x$ " $(M=5,41 ;$ d.p. $=1,47)$
Q1: Eu posso confiar no site " $x$ " $(M=5,52 ;$ d.p. $=1,36)$
Q2: 0 site " $x$ " tem as características de segurança necessárias a uma boa compra pela Internet $(M=5,74$; d.p. $=1,19)$
Q3: Eu obtive exatamente 0 que solicitei do site “ $x$ " $(M=6,21 ;$ d.p. $=1,19)$
Q2: 0 produto foi entregue no tempo (prazo) prometido pela empresa $(M=6,24 ;$ d.p. $=1,31$ )
Q1: 0 produto que recebi correspondia àquele apresentado no site " $x$ " (inclusive os detalhes do produto) $(M=6,38 ;$ d.p. $=1,18)$
Eu sinto que o site " $x$ " se preocupa com as necessidades dos consumidores $(M=5,42 ;$ d.p. $=1,29)$ No site " $x$ ", as pessoas do atendimento online (chat) estão sempre prontas para atender 0 cliente $(M=4,79$; d.p. $=1,87$ )
Quando eu tenho um problema, 0 site " $x$ " se apresenta interessado e sincero em resolver $(M=4,93$; d.p. $=1,76)$
Dúvidas e solicitações são respondidas prontamente pela empresa $(M=4,98$; d.p. $=1,73)$ 
tados mostraram que a confiabilidade de qualidade de design foi $\alpha=0,85$; a qualidade de segurança foi $\alpha=0,93$ e a qualidade de preenchimento foi $\alpha=0,75$. De modo geral, os resultados apontaram que a estrutura da e-TailQ obteve bons resultados tanto de confiabilidade, quanto de dimensionalidade.

Visando ainda à constatação da validade e dimensionalidade do instrumento, foi realizada uma análise fatorial confirmatória do modelo. Os achados foram ponderados pelos seguintes indicadores de ajustamento: Qui-Quadrado $\left(\chi^{2}\right) /$ Graus de Liberdade (g.l.); Nível de Significância ( $p$-valor); Goodness-of-Fit Index (GFI);
Adjusted Goodness-of-Fit Index (AGFI); Comparative Fit Index (CFI) Incremental Fit Index (IFI) e Root Mean Square Error of Approximation (RMSEA).

Como pode ser visto na Figura 1, todas as associações são positivas entre si. Em termos de correlação, os resultados mostraram que qualidade de design e qualidade preenchimento foram associadas significativamente, $\mathrm{r}=0,35(\mathrm{p}<0,001)$; qualidade de segurança e qualidade de design também $\mathrm{r}=0,72(\mathrm{p}<0,001)$ e, por fim, qualidade de segurança e qualidade de preenchimento $r=0,55$ $(\mathrm{p}<0,001)$. Infere-se que existe uma associação grande entre qualidade de segurança e qualidade de design, su-

Tabela 2 - Análise fatorial exploratória dos construtos da escala e-TailQ

\begin{tabular}{|c|c|c|c|c|}
\hline VARIÁVEIS & DES. & SEG. & PREEN. & соM. \\
\hline design_1: A organização e o layout do site " $\mathrm{x}$ " facilita a procura de produtos & 0,84 & & & $h^{2}=0,75$ \\
\hline design_7: Eu posso navegar rapidamente e de maneira precisa dentro do site " $\mathrm{x}$ " & 0,77 & & & $h^{2}=0,63$ \\
\hline design_6: 0 site "x" tem um apelo visual muito bom & 0,75 & & & $h^{2}=0,62$ \\
\hline design_2: 0 nível de personalização do site " $x$ " é ideal & 0,73 & & & $h^{2}=0,59$ \\
\hline design_3: É fácil e rápido completar uma transação de compra no site "x" & 0,68 & & & $h^{2}=0,61$ \\
\hline design_8: A aparência do site " $\mathrm{x}$ " parece ser profissional & 0,70 & & & $h^{2}=0,57$ \\
\hline design_4: Navegar pelo site "x" não desperdiça meu tempo & 0,60 & & & $h^{2}=0,50$ \\
\hline $\begin{array}{l}\text { design_9: } 0 \text { site " } x \text { " tem uma ampla variedade de produtos que acaba me } \\
\text { interessando }\end{array}$ & 0,43 & & & $h^{2}=0,35$ \\
\hline $\begin{array}{l}\text { security_4: Eu me sinto seguro quando eu estou fazendo transações/compras } \\
\text { com o site " } x \text { " }\end{array}$ & & 0,88 & & $h^{2}=0,88$ \\
\hline security_1: Eu posso confiar no site " $\mathrm{x"}$ & & 0,84 & & $h^{2}=0,84$ \\
\hline security_3: Eu sinto que minha privacidade está protegida utilizando esse site & & 0,86 & & $h^{2}=0,81$ \\
\hline $\begin{array}{l}\text { security_2: } 0 \text { site "x" tem as características de segurança necessárias a uma } \\
\text { boa compra pela Internet }\end{array}$ & & 0,77 & & $h^{2}=0,79$ \\
\hline $\begin{array}{l}\text { f1: } 0 \text { produto que recebi correspondia àquele apresentado no site " } x \text { " (inclusive } \\
\text { os detalhes do produto) }\end{array}$ & & & 0,79 & $h^{2}=0,67$ \\
\hline f3: Eu obtive exatamente o que solicitei do site " $x$ " & & & 0,79 & $h^{2}=0,69$ \\
\hline f2: 0 produto foi entregue no tempo (prazo) prometido pela empresa & & & 0,69 & $h^{2}=0,51$ \\
\hline Autovalor & 6,25 & 2,25 & 1,31 & \\
\hline \% Variância explicada de cada fator & $42 \%$ & $15 \%$ & $9 \%$ & \\
\hline \% Variância acumulada & $42 \%$ & $57 \%$ & $65 \%$ & \\
\hline Confiabilidade alpha & 0,85 & 0,93 & 0,75 & \\
\hline
\end{tabular}

Nota: des. $=$ design $;$ security $=$ seguranç $a ; f=$ preenchimento; com $=$ comunalidade 
gerindo uma possível relação do tipo: quanto mais design for percebido pelo usuário, maior será a percepção de segurança no momento da compra, ou quanto mais investimento em design, concomitantemente existe investimento nos quesitos de segurança para o usuário. Outro ponto visto é que a descrição precisa de um produto - de modo que consumidores recebam o que eles exatamente buscam e lhes seja entregue o produto correto dentro do tempo prometido - tende a aumentar a segurança $(\mathrm{r}=0,55 ; \mathrm{p}<0,001)$.

Partiu-se, em seguida, para uma avaliação mais específica do modelo de mensuração. Os resultados obtidos foram baseados no método de estimativa de distribuição livre assintótica (ADF), uma vez que não requer o pressuposto de normalidade multivariada (THOMPSON, 2004).

O modelo geral com correlação livre entre os fatores obteve os seguintes ajustes $\mathrm{AGFI}=0,74 ; \mathrm{GFI}=0,81 ; \mathrm{IFI}$ $=0,72 ; \mathrm{CFI}=0,72$ e RMSEA $=0,078$. O qui-quadrado relativo foi de $\chi^{2} / \mathrm{df}=2,97(p<0,000)$. O modelo rival de segunda ordem obteve os seguintes ajustes $\chi^{2} / \mathrm{df}=2,97 p$ $<0,000 ; \mathrm{AGFI}=0,74 ; \mathrm{GFI}=0,81 ; \mathrm{IFI}=0,72 ; \mathrm{CFI}=0,72$ e RMSEA $=0,078$, ou seja, os mesmos do modelo de pri- meira ordem, dada a grande similaridade entre eles. Apesar de o ajuste não ter sido o ideal em termos de adaptação perfeita do modelo, o mesmo não foi tão ruim a ponto de ser desprezado. Observa-se também que os ajustamentos confirmatórios foram similares ao trabalho de Bressolles e Nantel (2004).

Bagozzi e Philips (1982) salientam que a análise fatorial confirmatória também serve para fazer a avaliação da validade convergente dos construtos por meio da carga $t$-valor. Assim, os critérios sugerem que seja verificada a significância das cargas fatoriais dos construtos ao nível de 5\% ou $1 \%$. Nesse sentido, todos os achados apresentaram valores significativos a $p<0,001$ e valores $t$ variando entre 7,51 e 24,54, suportando a validade convergente da e-TailQ .

Assim, pode-se afirmar que a análise das propriedades psicométricas do instrumento e-TailQ mostrou-se válida. Constatou-se a existência de três construtos que são exatamente os sugeridos pela e-TailQ, demonstrando que as dimensões, tanto nos EUA quanto no Brasil, são bem próximas em termos de conceitualização e composição. Outra consideração importante se faz quanto à validade do instrumento, pois os achados mostraram que a con-

Figura 1 - Modelo confirmatório da medida de primeira ordem da qualidade e-TailQ

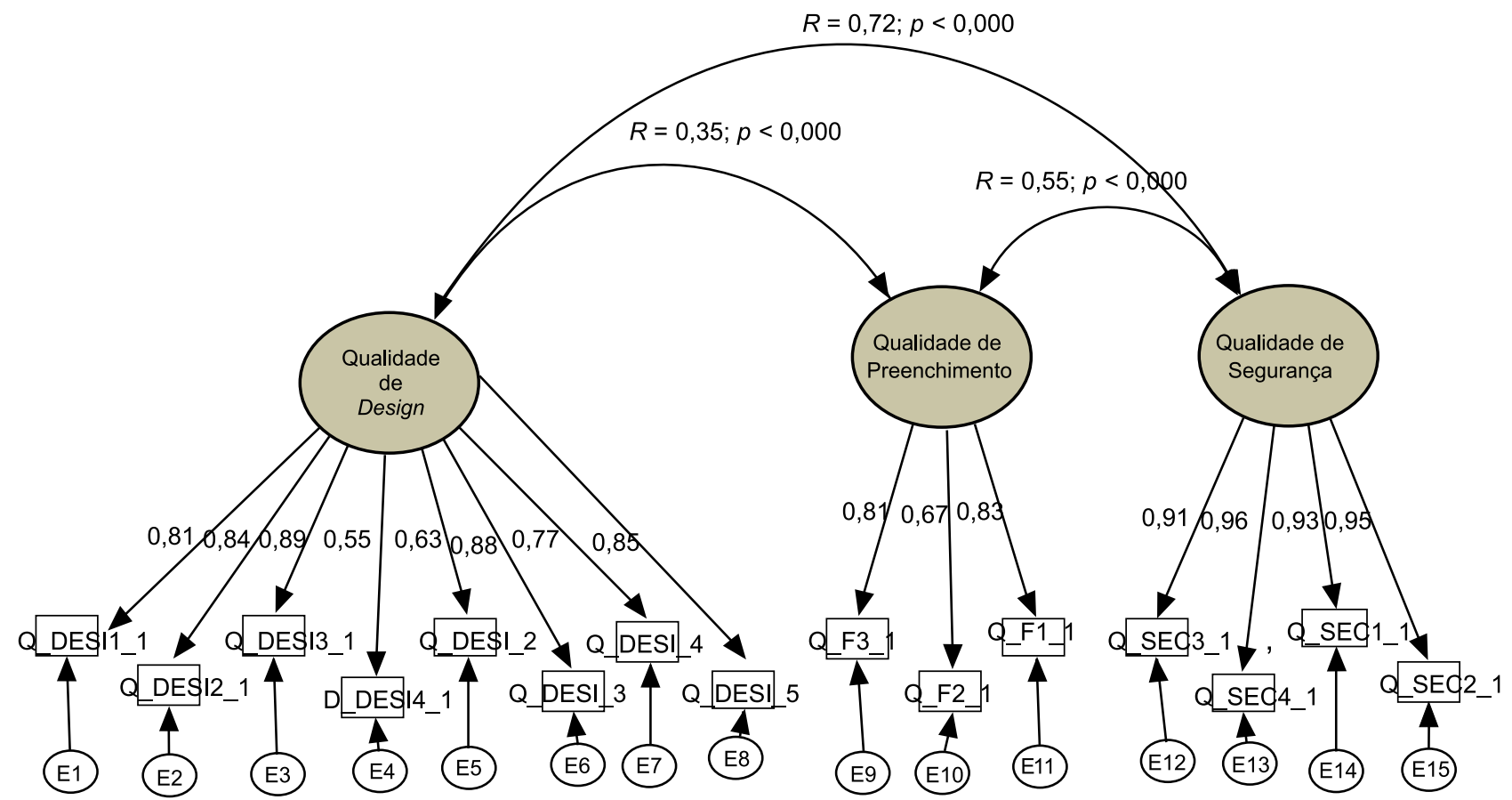

Nota: Valores padronizados das cargas fatoriais; estimativa de variância dos subconstrutos qualidade de design = 0,98; qualidade de preenchimento $=0,41$; e qualidade de segurança $=1,30$. 
fiabilidade da qualidade design ( $\alpha=0,85$ ); da qualidade de segurança $(\alpha=0,93)$ e da qualidade de preenchimento $(\alpha=0,75)$ foi alta em todos os construtos. Por fim, o modelo confirmatório obteve resultados moderados, indicando que a estrutura não reflete perfeitamente a realidade. Em outras palavras, a escala e-TailQ ainda necessita de outras dimensões ou variáveis para melhor refletir o fenômeno qualidade em ambiente virtual.

\section{ANÁLISE DOS RESULTADOS PARTE II: VALIDADE NOMOLÓGICA}

A literatura sugere evidências para determinadas associações. Cronin e Taylor (1992, p. 59) propõem que "as percepções que o consumidor tem de qualidade afetam suas intenções de compra". Se para Cronin e Taylor (1992) qualidade está relacionada com intenção de compra, e se para Oliver (1997) lealdade é um comprometimento em comprar novamente o produto, acredita-se que essas variáveis estão positivamente relacionadas. Assim, a hipótese $P_{1}$ é: Qualidade do site é correlacionada positivamente com lealdade.

Zeithaml (1988, p. 3) define qualidade "como a superioridade ou excelência do bem. Por extensão, qualidade percebida pode ser definida como o julgamento do consumidor sobre a excelência ou superioridade geral do produto". A idéia é de que uma excelência do bem cria uma percepção mais positiva dos benefícios recebidos pelo consumidor. Dado que Zeithaml (1988, p. 14) define valor como a "avaliação geral de utilidade de um produto baseado nas percepções do que é recebido sobre o que é dado", espera-se que quanto maior a qualidade apresentada pelo site, maior será o benefício ou a utilidade que o consumidor receberá. Assim, o raciocínio é de que maior qualidade, comprovada por um desempenho superior do bem, gera maior benefício da compra com menos custo para o consumidor. Parasuraman e Grewal (2002, p. 168-169) comentam:

É amplamente conhecido que valor percebido, sendo determinante-chave da lealdade, é proposto ser um componente do que se "consegue" [sobre] o que se "dá". [Nesse sentido], muitas das pesquisas sobre o valor percebido têm focado principalmente a qualidade do produto como um componente que se "consegue" [indicando] claramente qualidade do serviço como preditor lógico do valor.

Nessa situação, assume-se que $P_{2}$ : Qualidade do site é correlacionada positivamente com valor.
Expandindo a idéia da relação qualidade-satisfação para o ambiente virtual, algumas evidências eletrônicas sustentam a literatura tradicional. Por exemplo, nos achados de Wolfinbarger e Gilly (2003), duas dimensões de qualidade (design e cumprimento) foram preditoras da satisfação. No mesmo contexto, Gummerus e outros (2004) encontraram que a dimensão de qualidade de preenchimento foi significativa em explicar a satisfação com o site. Warrington (2002), por sua vez, encontrou que qualidade eletrônica estava relacionada positivamente com satisfação. Szymanski e Hise (2000) mostraram que alguns aspectos da qualidade impactavam significativamente a satisfação com a loja. Por último, Lee e Lee (1999), investigando 380 compradores coreanos na Internet, demonstraram significância na relação qualidade-satisfação. Assim, espera-se que a qualidade do varejista tenha um impacto positivo na satisfação. Com base nessa literatura, a hipótese proposta é $P_{3}$ : Qualidade do site é correlacionada positivamente com satisfação.

Investigações indicam relação positiva e significativa entre qualidade e boca-a-boca. Pressupõe-se que uma qualidade superior do varejista gere uma reação comportamental positiva. A qualidade do serviço e a intenção comportamental estão diretamente relacionadas e quanto maior a qualidade, maior tende a ser a comunicação do cliente com outras pessoas (ZEITHAML, BERRY e PARASURAMAN 1996). Portanto, a hipótese P4 é: Qualidade do site é correlacionada positivamente com boca-a-boca.

A Tabela 3 apresenta os valores de correlações entre as variáveis. O objetivo é verificar como o instrumento se comporta com outras variáveis de marketing. Nota-se que as relações foram em sua maioria positivas e próximas de uma média de rmédio $=0,45$. Contudo, a variável valor associou-se negativamente com todos os outros conceitos ponderados. Valor foi mensurado com o seguinte indicador "Eu obtenho uma boa relação de custo-benefício comprando no site ' $\mathrm{x}$ "' $(M=4,72 ;$ d.p. $=1,68)$.

Como possível explicação para esses resultados negativos de valor, acredita-se que o mesmo parece não ter sido percebido (ou obtido) no momento de compra eletrônica. Na prática uma complexidade operacional de realização da compra online, ou mesmo um cadastro de preenchimento extenso pode ter afetado a relação de custo-benefício percebido pelo usuário. Assim, consumidores estariam percebendo pouco valor na transação com o varejista

Após análise da matriz de correlação, foram empregados análises de regressão para verificar as quatro proposições de pesquisa. Primeiramente, qualidade eletrônica foi considerada um construto exógeno de segunda ordem (reflexo das três subdimensões design, preenchimento e 
segurança), e as variáveis observáveis foram consideradas endógenas no modelo (lealdade, satisfação, boca-a-boca, valor). Desse modo, visou-se verificar apenas se o fenômeno qualidade global tinha impacto nos outros quesitos avaliados. Em segundo lugar, qualidade eletrônica foi configurada como um construto de primeira ordem, em que foram utilizadas as três dimensões de qualidade como construtos de primeira ordem contra as variáveis de marketing. Assim, pressupõe-se que, se é dado que qualidade impacta a intenção de recomprar o bem, na satisfação do usuário e no boca-a-boca positivo, então exatamente quais construtos de qualidade impactam as mesmas variáveis? A Tabela 4 apresenta os resultados da primeira análise.

Diante das evidências da primeira análise, qualidade foi correlacionada positivamente com lealdade, apoiando a P1 e a literatura (CRONIN e TAYLOR, 1992; OLIVER, 1997). Na prática, a qualidade do site tende a induzir intenções de retorno ao mesmo. Qualidade foi correlacionada negativamente com valor, rejeitando a P2 e os argumentos elaborados (PARASURAMAN e GREWAL, 2000). Isso pressupõe o excesso da qualidade do site (tal- vez seu design e aparência) como um indicador de baixo valor agregado para o cliente. Como comparativo, Baptista e Mazzon (2006) e Vieira e Matos (2006) encontraram resultados não significativos na relação entre qualidade e valor. Qualidade foi correlacionada positivamente com satisfação, apoiando a P3 e a literatura (GUMMERUS e outros, 2004; WARRINGTON, 2002; WOLFINBARGER e GILLY, 2003). Por fim, qualidade foi correlacionada positivamente com boca-a-boca, corroborado a $\mathrm{P} 3$ e à bibliografia (ZEITHAML, BERRY e PARASURAMAN, 1996).

Após análise da qualidade como construto de primeira ordem, verificou-se o poder preditivo das três dimensões de qualidade sobre as variáveis de marketing. Os resultados podem ser vistos na Tabela 5 .

A qualidade de design teve associação positiva com lealdade, satisfação, boca-a-boca e não significativa com valor. O estudo de Wolfinbarger e Gilly (2003) também encontrou exatamente o mesmo resultado desta pesquisa. O resultado da relação qualidade de design-satisfação foi o mesmo de Szymanski e Hise (2000), indicando que design é um potencial explicador da satisfação em ambiente eletrônico.

Tabela 3 - Tabela de correlação das variáveis

\begin{tabular}{|c|c|c|c|c|c|c|c|}
\hline VARIÁVEIS & 1 & 2 & 3 & 4 & 5 & 6 & 7 \\
\hline 1. Qualidade de Design & 1 & & & & & & \\
\hline 2. Qualidade de Preenchimento & $0,35 * * *$ & 1 & & & & & \\
\hline 3. Qualidade de Segurança & $0,68 * * *$ & $0,43 * * *$ & 1 & & & & \\
\hline 4. Lealdade & $0,47 * * *$ & $0,32 * * *$ & $0,38 * * *$ & 1 & & & \\
\hline 5. Satisfação & $0,55^{* * *}$ & $0,52 * * *$ & $0,54 * * *$ & $0,37 * * *$ & 1 & & \\
\hline 6. Воса-а-Воса & $0,57 * * *$ & $0,44 * * *$ & $0,52 * * *$ & $0,44 * * *$ & $0,62 * * *$ & 1 & \\
\hline 7. Valor Percebido & $-0,57 * * *$ & $-0,35 * * *$ & $-0,38 * * *$ & $0,44 * * *$ & $-0,34 * * *$ & $-0,35 * * *$ & 1 \\
\hline
\end{tabular}

Nota: Todas as correlações são significativas à $p<0,001$.***

Tabela 4 - Regressão de qualidade de segunda ordem sobre as intenções comportamentais

\begin{tabular}{|l|c|c|c|c|}
\hline \multirow{2}{*}{ CONSTRUTO EXÓGENA } & \multicolumn{4}{c|}{ VARIÁVEIS ENDÓGENAS } \\
\cline { 2 - 5 } & LEALDADE & SATISFAÇÃO & BOCA-A-BOCA \\
\hline Qualidade varejo $2^{\mathrm{a}}$ ordem & $\beta=0,61^{* * *}$ & $\beta=0,76 * * *$ & $\beta=0,77^{* * *}$ & $\beta=-0,58 * * *$ \\
\hline$t$-value & 11,19 & 12,32 & 12,60 & $-9,49$ \\
\hline $\mathrm{R}^{2}$ Ajustado & $40 \%$ & $66 \%$ & $49 \%$ & $8 \%$ \\
\hline
\end{tabular}

Nota: $* * * p<0,001$; valores betas são padronizados; os resultados do modelo estrutural estimado em $\mathrm{ADF}$ foram: $\chi^{2} / \mathrm{d}$.f. $=3,43$; $\mathrm{AGFI}=$ 0,$79 ; \mathrm{GFI}=0,83 ; \mathrm{IFI}=0,73 ; \mathrm{CFI}=0,72 ; \mathrm{RMSEA}=0,083$. 
A qualidade de preenchimento teve associação positiva com lealdade, satisfação, boca-a-boca, mas significativa de modo negativo com valor. Conseqüentemente, comprova-se que a qualidade de preenchimento - a capacidade do site em descrever exatamente o que o indivíduo busca - é um forte preditor de lealdade. Wolfinbarger e Gilly (2003) também encontraram qualidade de preenchimento e qualidade de design como explicatórias de satisfação. Vieira e Torres (2008) confirmaram a relação entre qualidade de preenchimento e lealdade. Gummerus e outros (2004) encontraram que a dimensão de qualidade de preenchimento foi significativa em explicar a satisfação com o site.

A qualidade de segurança teve associação significativa apenas com o boca-a-boca, conforme também foi encontrado por Francis e White (2002). Qualidade de segurança proporcionada pelo varejista não impacta a intenção de retorno do consumidor. Isso pode ser explicado pelo fato de que compradores podem esperar aspectos de segurança como quesitos obrigatórios e não como um motivador adicional e potencial para a lealdade.

Portanto, somando os resultados da literatura com os dados empíricos aqui apresentados, assume-se que qualidade de design e qualidade de preenchimento são fatores-chave para a criação da satisfação do consumidor no varejo virtual. Satisfação teve um $\mathrm{R}^{2}$ de $44 \%$, criando assim a maior variância explicada pela estrutura da e-TailQ. Como interpretação, a qualidade de design e a qualidade de preenchimento no varejo eletrônico, quando bem organizadas e alinhadas, explicam grande parcela dos níveis de satisfação do usuário comprador.

No boca-a-boca, as três dimensões de qualidade eletrônica tiveram associações positivas e significativas. Portanto, somando esse achado ao resultado da primeira análise de regressão, a qualidade é fator determinante em induzir o comprador a falar positivamente do site.
Nota-se que a qualidade de preenchimento e a qualidade de design tiveram os maiores impactos no boca-a-boca. Todavia, mesmo com esse impacto, o $\mathrm{R}^{2}$ do mesmo foi baixo, chegando a $28 \%$.

Por fim, valor sofreu impacto significativo, porém negativo unicamente de qualidade de preenchimento Qualidade de preenchimento teve um peso beta de $-0,47$ sobre o valor, indicando um possível resultado. Primeiro, que quanto mais qualidade de preenchimento existe no site (descrição precisa do produto), menor é o valor percebido do cliente, talvez por criar uma confusão de sobrecarga de informação para o comprador. Esse achado negativo não foi esperado. Do mesmo ângulo de apreciação, o valor percebido teve correlação significativa negativa com quase todas as variáveis mensuradas (conforme Tabela 3). Assim, novamente as evidências apontam que o valor pode não ser notado pelos compradores. Conseqüentemente, futuros estudos poderiam verificar o motivo de tal associação invertida.

Outro diagnóstico deve ser salientado. No quesito de confiabilidade, cálculos da confiabilidade composta (CR) e da média da variância extraída (AVE) foram feitos a partir do modelo de mensuração na Figura 1. Pelos achados da Tabela 5, apenas o construto qualidade de design teve um valor abaixo de 0,50 na média da variância extraída Isso significa que $53 \%$ das informações geradas pela qualidade de design são devidos ao erro. Tomando no geral e excluindo esse pequeno problema, os valores de AVE e CR da e-TailQ tiveram boa performance.

\section{CONSIDERAÇÕES FINAIS}

Especificamente, este artigo buscou verificar as propriedades psicométricas do instrumento e-TailQ no varejo eletrônico brasileiro e também identificar a associação

Tabela 5 - Regressão dos fatores de qualidade de primeira ordem sobre as intenções comportamentais

\begin{tabular}{|c|c|c|c|c|c|c|}
\hline \multirow{2}{*}{$\begin{array}{l}\text { FATORES DE } \\
\text { QUALIDADE }\end{array}$} & \multicolumn{4}{|c|}{ VARIÁVEIS DEPENDENTES } & \multicolumn{2}{|c|}{ CONFIABILIDADE } \\
\hline & LEALDADE & SATISFAÇÃO & BOCA-A-BOCA & VALOR & CR & AVE \\
\hline Qualidade de Design & $\beta=0,18^{*}$ & $\beta=0,28 * * *$ & $\beta=0,31 * * *$ & $\beta=0,13$ & 0,87 & 0,47 \\
\hline $\begin{array}{l}\text { Qualidade de } \\
\text { Preenchimento }\end{array}$ & $\beta=0,59 * * *$ & $\beta=0,57^{* * *}$ & $\beta=0,34 * * *$ & $\beta=-0,47^{* * *}$ & 0,77 & 0,53 \\
\hline Qualidade de Segurança & $\beta=0,13$ & $\beta=0,05$ & $\beta=0,18^{*}$ & $\beta=-0,08$ & 0,94 & 0,79 \\
\hline $\mathrm{R}^{2}$ Ajustado & $25 \%$ & $44 \%$ & $28 \%$ & $7 \%$ & -- & -- \\
\hline
\end{tabular}

Nota: $* p<0,05 ; * * p<0,01 ; * * * p<0,001$; betas são padronizados; $\mathrm{CR}=$ confiabilidade composta; AVE = variância extraída; n.s. = não significativo. 
dos fatores do instrumento com variáveis de marketing. Como principais achados, a escala para mensurar qualidade em varejo eletrônico apresentou resultados muito bons nas três dimensões, em termos de confiabilidade, ajustamento, desempenho e dimensionalidade.

Todavia, dos quatro fatores inicialmente propostos, uma dimensão apresentou excesso de valores omissos (o respondente marcou "não sei" no questionário) e, portanto, o construto precisou ser excluído. Desse modo, a dimensão qualidade de serviço ao consumidor carece de maiores investigações. Duas possíveis explicações para esse resultado foram lançadas na análise e, nesse sentido, são necessários novos testes para verificar as reais causas dos valores em branco.

Segundo, os achados buscaram avançar na discussão da literatura sobre a qualidade, uma vez que ela é estudada com grande fervor no ambiente convencional, mas não na mesma proporção no ambiente virtual. No que tange a esse avanço, a qualidade de design obteve três relações significativas de quatro preditas, ou seja, com satisfação, boca-a-boca e lealdade. Essas evidências apontam que qualidade de design é um fator de avaliação expressivo do desempenho do site, um indicador da comunicação oral positiva entre pessoas para futuras compras e um determinante da revisita ao site.

Noutro ponto, qualidade de preenchimento teve relações significativas com lealdade, satisfação e boca-a-boca e significativa de modo contrário com valor. Qualidade de preenchimento (quando comparada com as outras dimensões de qualidade) teve impacto mais relevante em todas as variáveis de marketing, posicionando-se como a mais importante neste trabalho.

Por fim, qualidade de segurança teve impacto significativo somente na variável boca-a-boca. Vale salientar que o impacto único de segurança no boca-a-boca não significa menor importância deste no ambiente varejista. De fato, compras virtuais necessitam de aspectos bem fortalecidos e tecnologicamente avançados em termos de segurança e confiança, como foi apresentado por Vieira e Torres (2008) na relação entre qualidade de privacidade e confiança.

No geral, a estrutura da e-TailQ teve desempenho satisfatório nos quesitos avaliados e destacou as dimensões design e preenchimento como as mais fortes para explicar julgamentos dos compradores. Retirando o problema de exclusão de uma dimensão, o instrumento e-TaiQ é útil para mensurar o fenômeno da qualidade de serviços eletrônicos. Em resumo, os dezesseis itens finais purificados e listados no Quadro 2 podem auxiliar nos testes de futuras teorias em ambientes virtuais.

\section{Aplicações Gerenciais}

Primeiro, para o gestor de marketing a qualidade de design deve ser vista como uma ferramenta importante para a lealdade do cliente. Assim, condições de design, de visual, de layout, de rapidez, de organização de site, de navegação etc. ainda se configuram como extremamente relevantes para os gestores manipularem. Segundo, o instrumento validado pode auxiliar a detectar qual aspecto do lojista está sendo mais bem avaliado pelos consumidores. Nesse sentido, varejistas eletrônicos podem iniciar um processo de julgamento dos seus sites com a estrutura já validada, encontrando quais médias são superiores/inferiores. Terceiro, o instrumento e-TailQ pode ser útil para aferir periodicamente a qualidade do site pós-implementações de novos sistemas de pagamento, de bônus para cliente, de linguagem de programação como HTML vs. Flash Player etc., e quais dimensões de qualidade foram percebidas como melhores.

\section{Limitações da Pesquisa e Estudos Futuros}

Assim, a primeira limitação de pesquisa é o caráter transversal do método de pesquisa, o qual representa um obstáculo do presente estudo, uma vez que esta abordagem baseia-se na análise de um único momento. Futuros testes longitudinais poderiam avançar em novas descobertas de campo. Uma segunda limitação é o aspecto não probabilístico da amostra, o qual não permite fazer generalizações precisas para toda a população. Futuras pesquisas poderiam incluir cálculos amostrais para determinadas populações, gerando assim resultados mais plausíveis de generalização. Em terceiro momento, a idéia de mensurar lealdade, valor, boca-a-boca e satisfação via um único item poderia não refletir fielmente os construtos avaliados. Assim, trabalhos futuros poderiam utilizar variáveis latentes para cada um desses conceitos.

Outras pesquisas podem auxiliar na compreensão da qualidade no varejo eletrônico brasileiro, como, por exemplo, fazer comparações do desempenho dos diversos instrumentos de qualidade. A literatura aqui revisada indica outros instrumentos concorrentes a estrutura e-TailQ que podem explicar tanto quanto, ou mais, as intenções comportamentais. Portanto, comparações da e-TailQ com a WebQual, SiteQual, PIRQUAL etc. podem ser frutíferas.

Adicionalmente, artigos que utilizam a qualidade em relações varejistas business-to-business podem gerar resultados interessantes. Todavia, no ambiente business-toconsumer, a relação qualidade-satisfação pode ser mais fraca, uma vez que a cooperação e a parceria são menos salientadas, dada a facilidade de o comprador individual 
(versus empresarial) mudar de fornecedor (maior nível de concorrência). Pesquisas que comparam variáveis moderadoras nos dois ambientes podem auxiliar no desenvolvimento de novas teorias.

Finalmente, investigações em segmentos distintos podem analisar classes de consumidores com diferentes opiniões para os fatores de segurança, design e preenchimento. Assim, variações nos níveis da escala ocorreriam, dependendo do perfil demográfico do cliente. Portanto, trabalhos comparativos aplicados aos segmentos apresentados podem ser feitos utilizando o instrumento aqui verificado.

\section{REFERÊNCIAS}

ARNDT, J. Role of product-related conversation in the diffusion of a new product. Journal of Marketing Research, v. 1, n. 4, p. 291-295, 1967.

BAPTISTA, P. P; MAZZON, J. A. Relação entre qualidade percebida e lealdade do consumidor: um estudo aplicado ao setor varejista na Internet. In: ENCONTRO DE MARKETING da ASSOCIAÇÃO NACIONAL DOS PROGRAMAS DE PÓS-GRADUAÇÃO EM ADMINISTRAÇÃO, 2., 2006, Rio de Janeiro. Anais... Rio de Janeiro, EMA, 2006.

BAGOZZI, R. P, PHILIPS, L. W. Representing and testing organizational theories: a holistic construal. Administrative Science Quarterly, v. 27, n. 3 , p. $459-489,1982$.

BRESSOLLES, G, NANTEL, J. Electronic service quality: a comparison of three measurement scales. In: PROCEEDINGS OF THE EUROPEAN MARKETING ACADEMY CONFERENCE, 33., 2004, Murcia, Spain, EMAC, 2004.

CARUANA, A; EWING, M. T. The psychometric properties of eTail quality: na international investigation across product categories. International Marketing Review, v. 23, n. 4, p. 353-367, 2006.

CRONIN J. J; TAYLOR, S. A. Measuring service quality: a reexamination and extension. Journal of Marketing, v. 56, n. 3, p. 55-68, 1992.

FRANCIS, J. E; WHITE, L. Pirqual: a scale for measuring customer expectations and perceptions of quality in internet retailing. American Marketing Association Conference Proceedings, v. 13, p. 263-270, 2002.

GEFEN, D. Customer loyalty in e-commerce. Journal of the Association for Information Systems, v. 3, n.3, p. 27-51, 2002.

GUMMERUS, J; LILJANDER, V; PURA, M; VAN-RIEL, A. Customer royalty to content-based web sites: the case of an online health-care service. Journal of Services Marketing, v. 18, n. 3, p. 175-186, 2004

HAIR, J, ANDERSON, R.E, TATHAM, R, BLACK, W. Multivariate data analysis. New Jersey: Prentice Hall, 1998.
HERNANDEZ, J. M. Entendendo melhor o processo de decisão de compra na Internet: uma análise sobre o papel da confiança em diferentes. In: ENCONTRO NACIONAL DA ASSOCIAÇÃO NACIONAL DOS PROGRAMAS DE PÓS-GRADUAÇÃO EM ADMINISTRAÇÃO, 26 Salvador. Anais... Salvador, ANPAD, 2002

KLINE, R. B. Principles and practice of structural equation modeling. New York: Guilford Press. 1998

LEE, J, LEE, J. The influence of switching costs on customer retention: a study of the cell phone market in France. In: DUBOIS, B, LOWREY, T. M SHRUM, L. J, VANHUELE, M. European Advanced in Consumer Research v. 4, p. 277-283, Provo: UT, 1999

LOIACONO, E. T. Webqual: a web site quality instrument. PhD Thesis, University of Georgia, 2000.

MALHOTRA, N. Pesquisa de marketing. Bookman: Porto Alegre, 2001.

MATHWICK, C, MALHOTRA, N, RIGDON, E. Experiential value: conceptualization measurement and application in the catalog and internet shopping environment. Journal of Retailing, v. 77, n. 1, p. 39-56, 2001.

OLIVER, R. L. Satisfaction: a behavioral perspective on the consumer. New York: McGraw-Hill, 1997.

OLIVER, R. L. A cognitive model of the antecedents and consequences of satisfaction decisions. Journal of Marketing Research, v. 17, November, p. $460-469,1980$.

PARASURAMAN, A; GREWAL, D. The impact of technology on the qualityvalue-loyalty chain: a research agenda. Journal of the Academy of Marketing Science, v. 28, n. 1, p.168-174, 2000.

PARASURAMAN, A; ZEITHAML, V; BERRY, L. L. A conceptual model of service quality and its implications for future research. Journal of Marketing, v. 49, n. 2 , p. $41-50,1985$

PARASURAMAN, A; ZEITHAML, V; BERRY, L. L. SERVQUAL: a multipleitem scale for measuring consumer perceptions of service quality. Journal of Retailing, v. 64, n. 1, p. 12-40, 1988.

PARASURAMAN, A; ZEITHAML, V; MALHOTRA, A. E-S-QUAL a multiple-item scale for assessing electronic service quality. Journal of Academy Marketing Science, v. 7, n. 3, p. 213-233, 2005.

SZYMANSI, D. M; HISE, R. T. E-Satisfaction: an initial examination. Journal of Retailing, v. 76, n. 3, p. 309-322, 2000.

THOMPSON, B. Exploratory and confirmatory factor analysis: understanding concepts and applications. American Psychological Association Washington, DC, 2004.

VAN-RIEL, A; LILJANDER, V; JURRIENS, P. Exploring consumer evaluations of e-services: a portal site. International Journal of Service Industry Management, v. 12, n. 4, p. 359-377, 2001 


\section{VALTER AFONSO VIEIRA}

VIEIRA, V. A; MATOS, C. A. Uma análise dos antecedentes da lealdade no ambiente de varejo virtual: proposta e teste de um modelo teórico. ENCONTRO DE MARKETING da ASSOCIAÇÃO NACIONAL DOS PROGRAMAS DE PÓS-GRADUAÇÃO EM ADMINISTRAÇÃO, 2., 2006, Rio de Janeiro. Anais... Rio de Janeiro, EMA, 2006.

VIEIRA, V. A; TORRES, C. V. Verificação do instrumento E-S-Qual para mensuração da qualidade eletrônica no varejo. In: ENCONTRO DE MARKETING da ASSOCIAÇÃO NACIONAL DOS PROGRAMAS DE PÓS-GRADUAÇÃO EM ADMINISTRAÇÃO, 3., 2006, Curitiba. Anais... Curitiba, EMA, 2008.

VIEIRA, V. A; SLONGO, L. A. Um modelo dos antecedentes da lealdade no varejo eletrônico. Revista de Administração Contemporânea, v. 12, p. $40-60,2008$.

WARRINGTON, P. T. Customer evaluations of e-shopping: the effects of quality-value perceptions and e-shopping satisfaction on e-shopping loyalty. $\mathrm{PhD}$ (Thesis) Graduate College, University of Arizona, 2002.

WICKLIFFE, V. P. Refinement and re-assessment of the consumer decisionmaking style instrument. Journal of Retailing and Consumer Services, v. 11, n. 3, p. $9-17,2004$.

WOLFINBARGER, M; GILLY, M. C. e-TailQ: dimensionalizing, measuring and predicting e-tail quality. Journal of Retailing, v. 79, p. 183-198, 2003.
YANG, Z; FANG, X. On-line service quality dimension and their relationships with satisfaction: the content analysis of customer reviews of securities brokerage services. International Journal of Service Industry Management, v. 15, n. 3/4, p. 302-326, 2004.

YOO, B; DONTHU, N. Developing a scale to measure the perceived quality of an Internet Shopping INTERNETWORLDSTAT. Disponivel em http:// www.e-commerce.org.br/STATS.htm\#H. Quarterly Journal of Electronic Commerce, v. 2, n. 1, p. 31-46, 2001.

ZEITHAML, V. Defining and relating price, perceived quality and perceived value. Cambridge: MSI, 1987

ZEITHAML, V. A. Consumer perceptions of price, quality and value: a means-end model and synthesis of evidence. Journal of Marketing, v. 52, n. 3, p. 2-22, 1988.

ZEITHAML, V. A; BERRY, L. L; PARASURAMAN, A. The behavioral consequences of service quality. Journal of Marketing, v. 60, n. 2, p. 31-47, Apr.1996.

ZEITHAML, V. A; PARASURAMAN, A; MALHOTRA, A. A conceptual framework for understanding e-service quality: implications for future research and managerial practice. Working Paper. Marketing Science Institute, Cambridge MA, 2000. 